\title{
Study of Spatial Distribution of Potentially Toxic Elements in a Nature Reserve in Langata Ecosystem
}

\author{
Samwel Boaz Otieno ${ }^{1, ~ *, ~ E m m a n u e l ~ N g u m b i ~}{ }^{2}$, Christine Odhiambo-Nyan'gaya ${ }^{2}, J_{a g i}$ Gakunju ${ }^{2}$ \\ ${ }^{1}$ Department of Community Health, Great Lakes University, Nairobi Centre, Nairobi, Kenya \\ ${ }^{2}$ Africa Fund for Endangered Wildlife (AFEW) Kenya, Nairobi, Kenya
}

Email address:

samwelbotieno@yahoo.com (S. B. Otieno)

${ }^{*}$ Corresponding author

\section{To cite this article:}

Samwel Boaz Otieno, Emmanuel Ngumbi, Christine Odhiambo-Nyan'gaya, Jagi Gakunju. Study of Spatial Distribution of Potentially Toxic Elements in a Nature Reserve in Langata Ecosystem. Journal of Health and Environmental Research. Vol. 6, No. 4, 2020 , pp. 114-118. doi: $10.11648 /$ j.jher.20200604.12

Received: July 21, 2020; Accepted: October 7, 2020; Published: November 9, 2020

\begin{abstract}
Introduction: Study of Spatial distribution trends of potentially toxic trace (PTE) element pollution in Nature Reserves in Kenya soil has not been fully done. Pollution from potentially toxic trace elements (PTEs) suspected to be widespread in many parts of Kenya including Nature reserves. This is concidered a threat to wild animals and human health. This therefore necessitates a study to understand the extent of spatial distribution of PTE of much economic and health importance. Methods: About forty soil samples were taken in AFEW nature reserve in Langata Ecosystem at, 25 centimeters deep using soil augur. The samples in Ziplocs were transported to the chemistry labs. at Kabete and analyzed to determine levels of $\mathrm{Pb} \mathrm{Hg}, \mathrm{Co} \mathrm{Cr} \mathrm{Cu}, \mathrm{Zn}$ by Coupled Plasma (ICP) Atomic Emission Spectrophotometry (AES) Optima 8000, Perkin Elmer to determine various ions, the results are presented in mg/gm. Health Quotient (HQ), Health Index (HI) and Pollution Index was calculated from the results. Results: In the study, traces of Potential Toxic Elements $(\mathrm{Pb}, \mathrm{Hg}, \mathrm{Cd}, \mathrm{Cr}, \mathrm{Cu})$ were found in soil samples taken in varying quantities. Generally, there was higher levels near a stream in the reserve, $\mathrm{Pb}$ ranging from $0.9080 \mathrm{mg} / \mathrm{gm}$ to $3.6927 \mathrm{mg} / \mathrm{gm} ; \mathrm{Hg}$ varying from $1.8355 \mathrm{mg} / \mathrm{gm}$ to $3.4781 \mathrm{mg} / \mathrm{gm}$. All others showed variation with higher levels in batches (B2) near the stream. No Zinc and Aluminum was detected in the samples. Health Index due to five PTEs was 0.859. Conclusion: It can be concluded that there are significant level $\mathrm{Pb} \mathrm{Hg}$, and Cobalt in various transects, but more near the stream traversing the reserve. $\mathrm{HI}$ is $<1$ but should other PTEs in sample be included will likely be 1, meaning Health Hazard exists in the reserve to humans and animals. Pollution index was $>1$ for $\mathrm{Pb}, \mathrm{Hg}$, and Co suggesting pollution by lead and Mercury in the Reserve.
\end{abstract}

Keywords: Toxic, Elements, Spatial, Nature, Reserve

\section{Introduction}

In cases of farm land spatial trace elements analysis, the focus has mainly been on micronutrients of industrial importance [2]. The pollutants including $\mathrm{Cd}, \mathrm{Ni}, \mathrm{Cu}, \mathrm{Zn}$, and $\mathrm{Hg}$ have only occasionally been incidental finding in the spatial surveys or in cases of increased of poisoning. Potentially Toxic Elements (PTE) is associated with industrial dumping and sewage disposal [6]. This study may provide guidance for policymakers regarding the protection and high-risk area of PTE contamination in the soils.

Potentially toxic elements (PTEs) are of more importance due to their bio toxicity to humans and animals PTEs are persistent in the environment; are non-biodegradable and non-thermodegradable and thus readily accumulate to toxic levels [6]. There has been fear of entry into food chain either directly through consumption in contaminated water and vegetables or indirectly through animal products grazing in vegetation from the soils contaminated with PTE [2]. Rapid industrialization and processes associated with urbanization is contributing to PTE spatial distribution.

Other processes contributing to increase in PTE include waste runoff to collecting systems and waterways [5]. Atmospheric contamination of the urban sulage depend on the nature of surrounding industries, on the proximity of major emission sources such as metal smelters, foundry works and power stations. Potentially toxic element loads can be greater 
in sulage from commercial activities, than in residential areas Roof runoff and building runoff also contribute to the total sulage loading and may be a potential source of significant level of potentially toxic elements such as Zinc, Lead, Copper and Cadmium [8]. Road and roof runoff are very important during rainy season, which flushes potentially toxic elements and other pollutants from surfaces. the metal species released are usually dissolved, bioavailable form. However, these environmental sources very and depends on road traffic, type of roofs, and material used, weather conditions, and type of investment in the environment, artisan mining activities and extent of intensification of agriculture. Agro industries including leather turning which are expanding contributes to PTE spatial distribution as they are source of $\mathrm{Cd}$ [11].

PTE spatial distribution in soils is considered prevalent in artisan mining areas where minerals are extracted using Mercury, or where such elements are naturally occurring in the soil. Such areas in Kenya include Taita Taveta County, Western Kenya counties, and some parts of Rift Valley. Such contaminants likely find their way into food chain since they border farm lands. Some of the areas border wild life parks like the case of Trans Mara Gold mines. How these soil pollution is affecting food consumed is yet to be established in Kenya, especially the main grain producing areas like Kakamega. Studies already done are insufficient to reveal the status of PTE pollution in the nature reserve in Kenya, where the soil is spatially elaborate, without some uncertainties. Furthermore, there are limited reviews of soil PTE pollution in the main National Parks.

PTEs contaminate underground water hence has potential of entering and accumulating in the food chain $[12,2]$. They are both non-biodegradable, and persistent in the environment, hence has potential of accumulating in human body with serious health consequences [5]. Most of the PTE are toxic to animals and human beings at certain levels. These include $\mathrm{Pb}, \mathrm{Hg}, \mathrm{Cu}$, $\mathrm{Cr}$, Cd. Some of the PTE are known to lead to specific pathology in human beings $[1,2,10]$ these include Arsenic
(Visceral, liver and bladder cancer) Cadmium (renal disorders and osteoporosis), Lead causes Neuro-pathology leading to hyper activity, anemia and fatigue.

Toxic elements in tissues displaces some cations in water resulting in health toxicity. Lead tends to displace bivalent cations such as $\mathrm{Mg}^{2+} \mathrm{Ca}^{2+}$ and $\mathrm{Fe}^{2+}$ thereby indirectly leading neuropathology, anemia and fatigue $[2,3,11]$. The displaced toxic elements in turn, induces pathology in some cells [13]. $\mathrm{Pb}$ ions affects cells adhesion, ionic transportation, protein folding, leading to apoptosis, and affects cell signaling processes. The displaced Calcium $\left(\mathrm{Ca}^{2+}\right)$ ions are known to denature Protein kinase $\mathrm{C}$ responsible for memory storage and the regulation of neural excitation [4]. Aluminum when consumed, replaces. $\mathrm{Fe}^{3+}$ and $\mathrm{Mg}^{2+}$ in the body. This affects metabolic processes like cellular growth, intercellular interaction and secretory functions when Ferrous ions fails to bind with proteins in the body [7]. The ions further form free radicals affecting ferrous levels in biological fluids and cells [8], and in high concentrations, $\mathrm{Fe}^{+2}$ becomes corrosive and affects the gastrointestinal tract, penetration into the cells of the liver, heart and brain, and lipid peroxidation, causing damage to the mitochondria and microsomes. Further hydrogen-free-radicals derived from excessive absorption of iron are responsible for cellular damage, malignant alterations and mutation. Exposure to excess PTE leads to serious health consequences in both human and wild animals therefore constant exposure to environment containing PTE poses a serious risk to human and animal health.

Quality assessment of soil concentration of PTE is important as a way to monitor the potential quality of water consumed and crops consumed in order to safeguard human health, especially those dwelling within short distances of sources contaminants like artisan mines, factories and sewer disposal sites. Furthermore, the nutritional level of trace elements varies considerably in different species and the gap between their optimum and toxic requirements are quite narrow. Thus, exposure to an excess concentration trace elements proportions may lead to severe health effects.

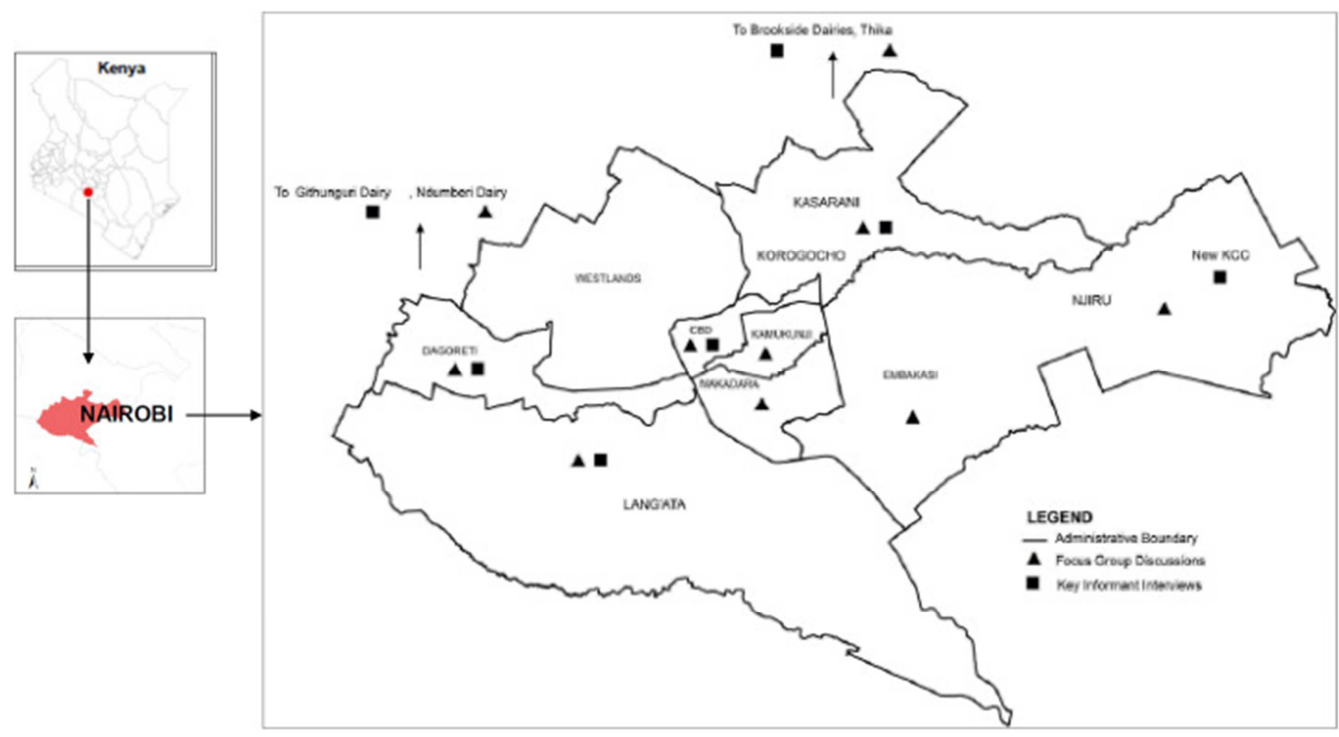

Ecosystem.pdf $\backslash \mathrm{C}: \backslash$ Users $\backslash$ user $\backslash$ Downloads $\backslash$ Langata Ecosystem.pdf.

Figure 1. MAP of Nairobi: Source Google Maps. 


\section{Materials and Methods}

\subsection{Sample Collection}

AFEW Kenya Nature Reserve in Langata Ecosystem Nairobi, is about 100 Acres. Sampling was done along pre-existing transects (animal tracks.) and geo referenced. Subsurface soil samples were collected at 25 centimeters depth. The cores were pooled mixed thoroughly and 250grams samples drawn. The samples were classified according to transects. The samples were put in Ziplocs at room temperature.

\subsection{Sample Analysis}

The samples were put in tight Ziplocs and transported to the chemistry lab at Kabete at room temperature for analysis. The analysis was done according to earlier methods [14, 15]. Samples were homogenized into fine powder using mixer grinder, sifted through a sieve and then dried to constant weight at $700 \mathrm{C}$. About $0.25 \mathrm{O}$ grams sample was added to graphite tube for digestion, $0.2 \mathrm{ml}$ of pure deionized water was added, followed by $8 \mathrm{ml}$ of $\mathrm{HNO}_{3}$ and digested for 24hrs, an additional $2 \mathrm{ml}$ of $\mathrm{HClO}_{4}$ was then added. Digestion temperature was regulated until clear color was obtained. Finally, Deionized water was added to increased remaining solution to $50 \mathrm{ml}$. Inductively Coupled Plasma (ICP) Atomic Emission Spectrometry (AES) Optima 8000, Perkin Elmer was used to determine various ions.

\subsection{Health risk analysis}

\section{(i) Hazard Quotient}

Health risk analysis was done using earlier model [9]. This was meant to extensively asses risk effects due to Toxic Elements in table 4. In this study, oral ingestion is the most common route of toxicity both in animals and humans hence considered the main significant pathway to toxicity [12]. Some toxic elements are likely to be carcinogens while some tend to cause other health effects when the exposure levels and rates are high, while others could be toxic over long period of time. In this study the evaluation based on US EPA standards for possible toxic effects is used. The hazard quotients (HQ), which is the ratio of the chronic daily intake (CDI) of individual toxic element to the Oral Reference Dose (RfD) was calculated as $\mathrm{HQ}=\mathrm{CDI} / \mathrm{RfD}$ oral ingestion. (Where HQ oral Ingestion represents the hazard proportion via ingestion, CDI Ingestion is the chronic daily intake via ingestion route). If $\mathrm{HQ}>1$, the population will experience health risk, while HQ $<1$ represents the acceptable level (population will pose no risk).

(ii) Hazard Index

The hazard index is the sum of the hazard quotients [14] and is calculated due to the presence of more than one toxic Element in the sample. It is assumed that the magnitude of the adverse effect in a sample will be proportional to the sum of several element exposures.

(iii) Pollution Index
The PI is the quotient of the concentration of the element $\mathrm{x}$ in the sample to the maximum permissible level of the element. Pollution Index=Element Concentration in sample/Possible limit/Background Value [16].

\section{Results and Discussion}

The soil analysis was done and is presented in form of tables as indicated below. They were grouped in transects. The level of various elements shown were expressed in $\mathrm{mg} / \mathrm{gm}$.

Table 1. Transect 1.

\begin{tabular}{llllll}
\hline Batch N & Al & Zn & Co & Pb & Hg \\
\hline B1S1 & 0 & 0 & 0.9598 & 2.1115 & 0.0114 \\
B1S2 & 0 & 0 & 0.6555 & 1.7177 & 0.0137 \\
B1S3 & 0 & 0 & 1.2938 & 2.9959 & 0.0139 \\
B1S4 & 0 & 0 & 0.8593 & 2.0522 & 0.0136 \\
B1S5 & 0 & 0 & 1.0315 & 2.3604 & 0.0133 \\
B1S6 & 0 & 0 & 0.9409 & 2.1821 & 0.0141 \\
B1S7 & 0 & 0 & 0.6753 & 1.4986 & 0.0138 \\
B1S8 & 0 & 0 & 0.8074 & 2.0538 & 0.0142 \\
B1S9 & 0 & 0 & 0.9176 & 2.1621 & 0.0144 \\
B1S10 & 0 & 0 & 0.6268 & 2.1994 & 0.0128 \\
\hline
\end{tabular}

Table 2. Transect 2.

\begin{tabular}{llllll}
\hline Batch1 & Zn & Co & Pb & Hg & Al \\
\hline B2S1 & 0 & 0.7651 & 2.3264 & 2.1938 & 0 \\
B2S2 & 0 & 1.2525 & 3.6927 & 3.4781 & 0 \\
B2S3 & 0 & 0.9239 & 2.6058 & 2.4822 & 0 \\
B2S4 & 0 & 0.7653 & 2.5742 & 2.9231 & 0 \\
B2S5 & 0 & 0.7653 & 2.5742 & 2.5521 & 0 \\
B2S6 & 0 & 1.0067 & 2.7855 & 2.6511 & 0 \\
B2S7 & 0 & & & & 0 \\
B2S8 & 0 & 0.6237 & 1.9316 & 1.8257 & 0 \\
B2S9 & 0 & 0.5589 & 2.0981 & 1.9836 & 0 \\
B2S10 & 0 & 0.4537 & 1.9502 & 1.8355 & 0 \\
\hline
\end{tabular}

Table 3. Transect 3.

\begin{tabular}{llllll}
\hline & Co & Pb & Hg & Al & Zn \\
\hline B3S1 & 2.1078 & 2.3928 & 0.0114 & 0 & 0 \\
B3S2 & 1.5486 & 1.9944 & 0.0118 & 0 & 0 \\
B3S3 & 0.8658 & 0.9080 & 0.0111 & 0 & 0 \\
B3S4 & 1.5042 & 1.2146 & 0.0112 & 0 & 0 \\
B3S5 & 1.3893 & 1.3477 & 0.0123 & 0 & 0 \\
B3S6 & 1.3681 & 1.3258 & 0.0125 & 0 & 0 \\
B3S7 & 1.8989 & 1.0244 & 0.0114 & 0 & 0 \\
B3S8 & 0.6600 & 1.3942 & 0.0116 & 0 & 0 \\
B3S9 & 0.3908 & 1.3942 & 0.0116 & 0 & 0 \\
B3S10 & 0.6268 & 2.1994 & 0.00128 & 0 & 0 \\
\hline
\end{tabular}

Table 4. Average Concentration of PTE and Chronic Daily Intake $n$ different Transects.

\begin{tabular}{llllllllll}
\hline \multicolumn{4}{c}{$\begin{array}{l}\text { Average concentration Of PTE } \boldsymbol{\mu} / \mathbf{g m} \\
\text { (Soil) }\end{array}$} & \multicolumn{4}{c}{ CDI $\boldsymbol{\mu} / \mathbf{g m}$ (Water) } \\
\hline PTE & Al & Zn & Co & Pb & Hg & Al & Co & Pb & Hg \\
\hline T1 & 0 & 0 & 0.87679 & 2.1337 & 0.01352 & 0 & 65 & 160 & 1.014 \\
T2 & 0 & 0 & 0.49057 & 2.5043 & 2.436133 & 0 & 36 & 187 & 182 \\
T3 & 0 & 0 & 1.23608 & 1.51955 & 0.010618 & 0 & 92 & 113 & 0.796 \\
Average & & & & & 0 & 64 & 353 & 61 \\
\hline
\end{tabular}


Health quotient was calculated as follows,

$$
\mathrm{HQ}=\mathrm{CDI} / \mathrm{RfD} \text {, }
$$

Table 5. Hazard Quotient (HQ) and Pollution Index of TSE at the Reserve.

\begin{tabular}{llllll}
\hline & $\mathbf{P b}$ & $\mathbf{H g}$ & $\mathbf{C o}$ & $\mathbf{A l}$ & $\mathbf{Z n}$ \\
\hline Non-Carcinogenic Health Risk & 0.723 & 0.13 & 0.00059 & 0 & 0 \\
Pollution Index & 5.09 & 3.073 & 3.39 & 0 & 0 \\
\hline
\end{tabular}

Health Risk Index was then computed based on HQ of each PTE as follows:

$$
\begin{aligned}
& \mathrm{HI}=\Sigma(\mathrm{HQ})=\mathrm{HQPb}+\mathrm{HQHg}+\mathrm{HQCo}+\mathrm{HQAl}+\mathrm{HQZn} \\
& \mathrm{HI} \text { Index }=\Sigma \mathrm{HQ}=0.723+0.129+0.00059+0+0=0.8540
\end{aligned}
$$

(Transects 1, 2 and 3) show various PTE being found in soils in Reserve.. These were distributed in various areas of the 100 acres covered by the reserve. From longitude 1.37726 latitude36.74647 and longitude -1.37583 latitude 36.74777 (B1); longitude -1.37551 and latitude 36.74789 (B2) and longitude 1.3764 latitude 36.7494 (B2); and longitude 1.37605 latitude 36.74814 (B3). The PTEs Lead, Mercury and Cobalt were detected in the sampled area with higher level being detected nearer the stream in the reserve compared to further away. Mercury was in higher level in B2 transect compared to other transects, varying from $1.8355 \mathrm{mg} / \mathrm{gm}$ furthest from the reserve to $3.4781 \mathrm{mg} / \mathrm{gm}$ nearest stream. Similarly lead $(\mathrm{Pb})$ had variation with higher level in B2 $(3.6927 \mathrm{mg} / \mathrm{gm}$ nearest the stream to 0.9089 $\mathrm{mg} / \mathrm{gm}$ ) on further away. Zinc ( $\mathrm{Zn})$ and Aluminum was not detected in the three transect sampled (0). This variation which shows pattern associated with proximity to the stream tends to support earlier observation by Guagiliardi et al.,
2016, It is also possible that they could be due to air borne contamination reported earlier by Martha et al., 2013 as the sampling point is also near a busy road. The presence of these PTE present possible contamination of pastures at Reserve where Giraffe grazes, and can easily lead to poisoning to humans downstream. The Hazard quotient for three elements $\mathrm{Pb}$., $\mathrm{Hg}$ and $\mathrm{Co}$ was 0.845 .

Health Risk to staff /and animals at AFEW was assessed based on the soil data as a proxy. -indicator of TSE consumed in bore hole water. As basic need it was estimated that in a day an adult consumes four tumblers of water (about 1 litre) per day during working hours, and this contributes in a large part of their daily intake of PTEs. The results indicate that toxic metals are found in high concentrations in soils, indicating a health risk assessment is essential. Assessment of potential health effects of human contamination of toxic metals through the consumption of water includes carcinogenic and non-carcinogenic. On assessment Health Risk indicate variation with in the order $\mathrm{Pb}>\mathrm{Hg}>\mathrm{Co}>\mathrm{Zn} / \mathrm{Al}$, in various transects in the study area. Lead had the highest HQ of 0.723 , followed by Mercury at 0.13 , cobalt with 0.00059 and finally aluminum and Zinc at 0 . Although the Health Risk Index is relatively low $<1$, (But Close) cumulative and variation in quantity of water consumed, may still lead to some staff having higher risk than others. These risks could be higher to Giraffes in the reserve since they consume large quantity of water per day.

Pollution Index (PI) results show that the soils in the Nature reserve is contaminated with Lead, Mercury and Cobalt as PI $>1$. How ever there was no contamination of $\mathrm{Zn}$, and $\mathrm{Al}$ as the PI index is $<1$.

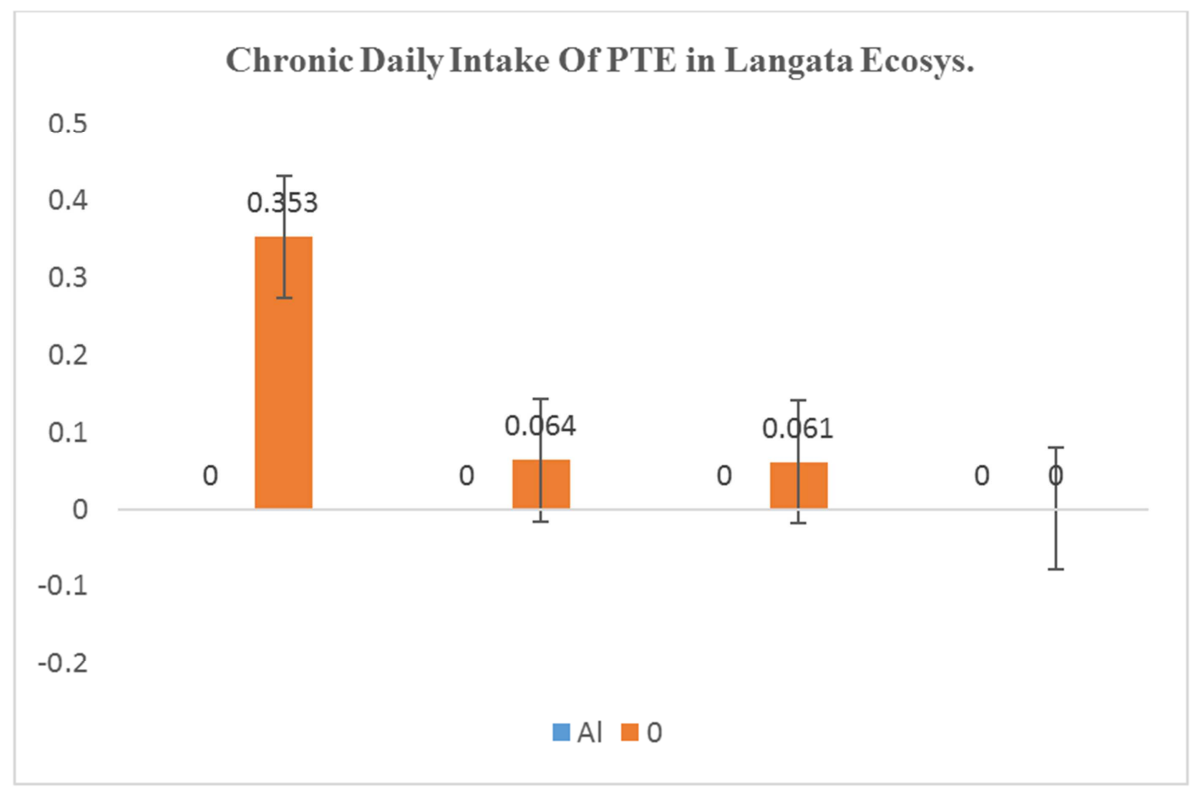

Figure 2. CDI of PTEs in Site $\mathrm{Pb}, \mathrm{Hg}, \mathrm{Co}, \mathrm{Zn}$, and $\mathrm{Al}$.

\section{Recommendation}

From the study it is apparent that all the transects had traces of PTE. The variation of the amount suggests that either the roads or the river is contributing to the PTE as the levels are higher in the in an area of land between the two 
(B2). Further analysis suggests that $\mathrm{HI}$ although $<1$ is close suggesting that if all PTE is considered the HI is likely to be 1. This suggests that there is potential risk of health hazard to staff/animals in or near Langata Forest Reserve at the AFEW. Further research need to be done to determine whether the contamination is from the dust/fumes of the vehicles or from seepage of contaminated river traversing the sanctuary.

\section{References}

[1] Adriano DC (2001) Trace elements in terrestrial environment: Biogeochemistry, bioavailability, and risks of metals, Springer, Ney Yolk, 123-31.

[2] Clarke L M, DG Harvey, DJ Humphreys (1981), Veterinary Toxicology, ELBS Second Edition, ISBN 070200897 4; 123.

[3] Bassil, M. (2010). Lead, cadmium and arsenic in human milk and their socio-demographic and lifestyle determinants in Lebanon. Chemosphere 191, 911-921.

[4] Jaishankar, M., Tseten, T., Anbalagan, N., Mathew, B. B. \& Beeregowda, K. N.(2014) Toxicity, mechanism and health efects of some heavy metals. Interdisciplinary. Toxicology 7, $60-72$.

[5] European Commission (2001) Final Report prepared by ICON Consultants; UK 2001.

[6] Guagliardi I, Nicola Ricca, Loredana Bastone Maria Grazia Cipriani, Donata Civitelli, Anna Lia Gabriele Gabriele Buttafuoco (2016): Studying potentially toxic trace elements in soil-plant system: a case study of an olive orchard in southern, Italy (Calabria) Rend. Online Soc. Geol. It., Vol. 38 (2016) 59-61, Italy.

[7] Mara, D, Horan, N. Te, (2003); Handbook of Water and Wastewater Microbiology. (Academic, 2003).

[8] Martha A. Sánchez-Martínez, Ana J. Marmolejo-Rodríguez*, Víctor R. Magallanes-Ordóñez, Alberto Sánchez-González (2013), Vertical accumulation Centro Interdisciplinario de Ciencias Marinas del Instituto Politécnico Nacional, Av. IPN s/n, Col. Playa Palo de Sta. Rita, 23096 La Paz, Baja California Sur, Mexico.

[9] Mattla. Bi H. Grc `man, T. Kralj, F. Madrid, E. D1'azBarrientos, and F. Ajmone-Marsan (2007), Potentially Toxic Elements Contamination in Urban Soils: A Comparison of Three European Cities, Journal of Environmental health; 7175 .

[10] US Environmental Protection Agency (US EPA) (1989), Risk Assessment Guidance for Superfund: Human Health Evaluation Manual (Part A): Interim Final, U.S. Environmental Protection Agency, Washington, DC, USA.

[11] WHO. (2010) Childhood lead poisoning. 26.

[12] WHO, (2004) WHO Guidelines on Safety Monitoring of Herbal Medicines in Pharmacovigilance Systems, World Health Organization, Geneva, Switzerland, 2004, https://apps.who.int/medicinedocs/documents/s7148e/s7148e. pdf.

[13] Praise God Chidozie Emenike, Imokhai Tenebe, Nkpa Ogarekpe, (2019) Probabilistic risk Assessment and spatial distribution of potentially toxic elements in groundwater sources in Southwestern Nigeria; Scientific Reports, Nature 9: 15920.

[14] Paula F. S. Tschinkel, 1 Elaine S. P. Melo, 1 Hugo S. Pereira, 2 Kassia R. N. Silva, 2 Daniela G. Arakaki, 1 Nayara V. Lima, 1 Melina R. Fernandes, 1 Luana C. S. Leite, 1 Eliane S. P. Melo, 1 Petr Melnikov, 1 Paulo R. Espindola, 1 Igor D. de Souza, 1 Valdir A. Nascimento, 1 Jorge L. R. Ju'nior, 2 Ana C. R. Geronimo, 1 Francisco J. M. dos (2020) The Hazardous Level of Heavy Metals in Different Medicinal Plants and Their Decoctions in Water: A Public Health Problem in Brazil; Hindawi Biomedical International, vol. 2020: 1-11.

[15] N. Zheng, J. Liu, Q. Wang, and Z. Liang, "Health risk assessment of heavy metal exposure to street dust in the zinc smelting district, Northeast of China," Science of @e Total Environment, vol. 408, no. 4. 726-733, 2010.

[16] Zheng N, Liu J, Wang Q, Liang Z,. (2010) Calculating Pollution Indices by Heavy Metals in Ecological Geochemistry Assessment and a Case Study in Parks of Beijing: Sci Total Environ. 2010 Jan 15; 408 (4): 726-33. 